"the unscrupulous a ready means of perpetrating their deeds of darkness." I will not dwell upon this objection, because I think it unfair to argue against a remedy on the ground of the abuses to which unprincipled persons may apply it. Such an objection would be out of place when addressed to the practitioners of medicine. But I fear we shall hardly be justified in concluding that these agents are altogether safe from some kind of abuse even in the hands of legitimate practitioners. There arise in practice frequent temptations to expedite delivery by the forceps; and when one great objection to their use, the pain apt to be inflicted, is removed, we cannot resist the conviction that they will often be resorted to unnecessarily. The sensitive mind shrinks from contemplating the mischiefs that will result. In Great Britain one mother in twenty dies under the forceps, and more than one child in five; to say nothing of lacerations, contusions, and other deplorable evils.-(Churchill.)

Because I demurred to accepting the arguments advanced by Dr. Simpson in favour of the use of chloroform in natural labour, the stupid charge of "inhumanity" has been directed against me. It remains to be proved whether the interest of "humanity" sanctions the general employment of chloroform in midwifery, or whether it does not emphatically condemn it. On this subject I cannot better express my own feelings than in the words of one of the most reflective writers of the present day-my colleague, Dr. Tyler Smith. The quotation is as applicable now to chloroform as it was a year ago to ether. "More recent experience has certainly not been in favour of enlarging the limits of its applicability in practical midwifery. In our own department there is good reason to believe, that after a short time, unless some certain mode of binding or disciplining this Prometheus shall be discovered, it will be rarely, if ever, used in difficult parturition or obstetric operations, and certainly never in natural labour. It will be a disappointment to have to turn from this promised good; but it is better to do so than to follow an ignis fatuus, if so it prove, to the neglect of real and scientific advancement. Let us hope that this glimpse of deliverance from this heavy infliction on humanity may act as a stimulus to Science to continue her search after some certain and available relief from physical pain, possibly a visionary search, but still one for which human nature will never cease to yearn."**

Having discussed one or two objections which have struck me on perusal of reported cases, I will avail myself of this opportunity to protest against the unfair treatment to which Dr. Meggison has been exposed in some recent comments upon the late fatal case at Newcastle. There is no part of Dr. Henry Bennet's paper which has given me more pain than that in which, falling into error as to facts, he abets Dr. Simpson in inflicting a great injustice on a brother practitioner. Dr. Simpson, with more ingenuity than success, laboured to show that Dr. Meggison's patient " did not die from the effects of chloroform, but from the effects of the means used to revive her." In other words, that Dr. Meggison killed his patient by improper interference. Dr. Bennet pleads for the credit of chloroform at the expense of Dr. Meggison in a similar manner, but makes him destroy his patient by different means. It appears to Dr. Bennet that the fatal event was probably owing to the neglect of the precautions of using a thin pocket handkerchief for the chloroform, and allowing the patient occasionally to breathe atmospheric air. Assuming that the chloroform was poured upon a table-cloth, and that this was kept closely in contact with her mouth and nostrils, Dr. Bennet infers that death was principally owing to asphyxia caused by the want of oxygen in the lungs. An appeal to the elements of physiology will expose the absurdity of Dr. Simpson's attempted exculpation of chloroform; an appeal to facts will set aside Dr. Bennet's. John Payne deposed at the inquest as follows:- "Dr. Meggison held a pocket-handkerchief to her mouth and nose; he kept it moving at times." An appeal to common sense will confirm the verdict of the jury founded on the competent evidence of Sir John Fife and Dr. Glover, that the "deceased died from congestion of the lungs produced by chloroform."

It is surely riding a hobby somewhat too hard, when all its mishaps are saddled on those who use it. The history of this unfortunate case may, however, furnish a useful lesson to those who are inclined to submit their judgments to the new obstetric dictator. Should they, governed by his authority, rashly adopt his practice, and, disappointed in the results, be visited with public censure, let them not hope that Dr. Simpson will come forward to protect them. He will direct against them individually the blame that should be imputed to his

* Lecture on Inhalation of Ether in Qustetric Practice, The LANcer, March 27th, 1847. own advice. While listening to Dr. Simpson's persuasions to use chloroform in every case of natural labour, it should be remembered that his credit is pledged to its universal adoption. Before the result of twelve cases was known to him, he had already drawn the conclusion, that it ought to be resorted to in every case of natural parturition. He had enforced his own premature conviction, by declaring that medical men may oppose for a time the superinduction of anssthesia in parturition; but they will oppose it in vain, for certainly our patients themselves, and their friends, will force the use of it upon the profession." The profession may rest assured that this argumentum ad crumenam is no better founded than Dr. Simpson's other arguments. The almost universal feeling of the well-educated women of this country is resolutely opposed to the idea of abandoning the highest prerogative bestowed upon mankind, for the sake of tiying from physical pains when by so doing they may heedlessly run into other and more serious evils that they know not of.

Gloucester-terrace, Hyde-park, 1848.

\section{ASIATIC CHOLERA: ITS PATHOLOGY AND} TREATMENT.

By E. V. MLAINWARING, M.D., Bournemouth.

WrTh your permission, I will answer Dr. Armstrong's letter, he having mistaken the effect of disease for a cause.

His letter in The Lancet (p. 375) says: "The black blood in cholera is probably caused by the spasm of the diaphragm and other muscles of respiration preventing the lungs from carrying on their functions, and consequently impeding the process of arterialization."

I will ask the doctor how he accounts for the "spasm of the diaphragm and other muscles"? If it be not produced by a poisonous gas, by what is it produced?

The doctor seems to despise tartarized antimony as a remedy in cholera; but as I have observed undoubted good effects from its use, I do not hesitate to recommend the treatment to others, even as a sedative. Tartar-emetic may relieve the "spasm of the diaphragm and other muscles."

The counter-irritation, opium, and stimulants, with one or two moderate doses of calomel-treatment which Dr. Armstrong prefers - I have known to fail in more instances than one.

The doctor says, "as far as his experience goes, Asiatic cholera is no respecter of persons." In this country it appears to have been more discriminating, its attacks being principally to the ill-fed, ill-lodged, and intemperate portion of confined the inhabitants.

The cholera in India, being more general in its attacks, may be accounted for by observing that the towns and cities are generally built on swampy ground, and near large rivers having inefficiently ventilated houses and streets, with bad drainage-a combination of evils, in a hot climate, enough to affect the high and the low, the rich and the poor; and if we take into consideration the enervating habits of the higher classes in India, it will be easily understood why " cholera is no respecter of persons" in that country. An individual may be "a regular liver," as far as eating and drinking are concerned, but eating and drinking are not the only causes of debility, and consequently are not the only evils to be avoided. A ride in the hot sun, distress of mind, over-exertion, \&c., or a single excess of any kind, will produce a liability to the dis. ease when the poison is rife in the air.

In conclusion, I beg to observe, that the treatment mentioned in a former paper having proved successful in this country, it is its best recommendation; and in the event of a recurrence of the Asiatic cholera, I think it deserving a faiz trial.

Bournemouth, Hants, 1848.

\section{ON A NEW PRINCIPLE IN THE TREATMENT} OF ASPHYXIA FROM SUBMERSION IN WATER OR PURE CARBONIC ACID.

By WILLIAM REID, M.D., Liverpool.

I BEG leave to suggest, as an improvement in the method of treating the apparently asphyxiated from submersion, the admixture of a certain anıunt of chlorine gas, or perhaps nitrous oxide-though I would give the preference to the formerwith the atmospheric air used in insufflation of the lungs, or artificial respiration This $I$ am led to propose, on the prin- 